\title{
ИССЛЕДОВАНИЕ ЭЛЕКТРОХРОМНЫХ ПЛЕНОК WО (GO), ПОЛУЧЕННЫХ ЭЛЕКТРОХИМИЧЕСКИМ ОСАЖДЕНИЕМ: ОПТИЧЕСКИЕ И ЭЛЕКТРОМАГНИТНЫЕ СВОЙСТВА
}

\author{
А. В. Щегольков, Л. Г. Князева, А. В. Щегольков, Ф. Ф. Комаров, И. Д. Парфимович \\ АЛЕКСЕЙ ВИКТОРОВИЧ ЩЕГОЛЬКОВ - аспирант кафедры «Техника и технологии производства \\ нанопродуктов», ФГБОУ ВО ТГТУ. E-mail: alexxx5000@mail.ru.
}

ЛАРИСА ГЕННАДЬЕВНА КНЯЗЕВА - д.х.н., дочент, главный научный сотрудник ФГБНУ ВНИИТ и Н. E-mail:fgbnuvniitin@mail.ru.

АЛЕКСАНДР ВИКТОРОВИЧ ЩЕГОЛЬКОВ - к.т.н, доиент кафедры «Техника и технологии производства нанопродуктов», ФГБОУ ВО ТГТУ. E-mail: energynano@yandex.ru.

ФАДЕЙ ФАДЕЕВИЧ КОМАРОВ - д.ф.-.м.н., заведующий лабораторией НИИПФП им. А.Н. Севченко БГУ. E-mail:komarovF@bsu.by.

ИВАН ДМИТРИЕВИЧ ПАРФИМОВИЧ - аспирант Белорусского государственного университета.

E-mail: irongrivus71@gmail.com.

392000, г. Тамбов, ул. Советская, д. 106. Тамбовский государственный технический университет (ФГБОУ ВО ТГТУ).

392022, г. Тамбов, пер. Ново-Рубежный 28. Всероссийский научно-исследовательский институт использования техники и нефтепродуктов в сельском хозяйстве (ФГБНУ ВНИИТиН).

220045 Республика Беларусь, г. Минск, ул. Курчатова 5. Научно исследовательсктй институт прикладных физических проблем им. А.Н. Севченко БГУ.

В статье приведены результаты исследований оптических и электромагнитных свойств электрохромных нанокомпозиционных пленок $W O_{3}$, модифицированных оксидом графена $(G O)$, полученных методом электрохимического осаждения ионов $W^{+}$и GO- из раствора перокси-вольфрамовой кислоты (ПВК) $W_{2} O_{11}^{2-}(G O)$. Реализован управляемый процесс электрохимического осаждения электрохромных пленок $W O_{3}$, который осуществлялся с помощью катодного осаждения, при котором задавались начальное и конечное значение потенциала электроосаждения -0,5 и-1,5 B, а также количество ичиклов.

Ключевые слова: электрохимическое осаждение, триоксид вольфрама, оксид графена. 


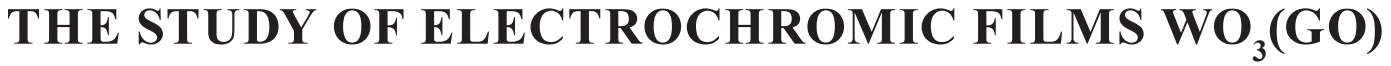 OBTAINED BY ELECTROCHEMICAL DEPOSITION: OPTICAL AND ELECTROMAGNETIC PROPERTIES
}

\author{
A. V. Shchegolkov ${ }^{1}$, L. G. Knyazeva ${ }^{2}$, A. V. Shchegolkov ${ }^{1}$, F. F. Komarov ${ }^{3}$, I. D. Parfimovich ${ }^{3}$ \\ 1106, Sovetskaya Str., Tambov, 392000, Russia. Tambov State Technical University.
}

\begin{abstract}
228 per. Novo-Rubezhnyi, Tambov, 392022, Russia. All-Russian Scientific Research Institute for the Use of Machinery and Oil Products in Agriculture.
\end{abstract}

37 Kurchatova str., Minsk, 220045, Republic of Belarus. A.N. Sevchenko Institute of Applied Physical Problems of Belarusian State University.

The article shows the result of studies of the optical and electromagnetic properties of electrochromic nanocomposite films $\mathrm{WO}_{3}$ obtained by electrochemical deposition with modified graphene oxide $(G O)$ with $\mathrm{W}^{+}$and $G O$-from a solution synthesized with peroxy-tungsten acid (PTA) with the addition of GO. The controlled process of electrochemical deposition of electrochromic films $\mathrm{WO}_{3}$, which was carried out by the method of multistage amperometry (MSA), which set the initial and final values of the electrodeposition potential of $-0,5$ and $-1,5 \mathrm{~V}$, also has a number of cycles.

Keywords: electrochemical deposition, tungsten trioxide, graphene oxide.

Из широкого многообразия, так называемых «умных материалов», выделяют особый класс материалов, известных как хромогенные, позволяющие контролировать отраженный или рассеянный свет, проходящий через них, в результате внешнего управляющего воздействия [1], такие материалы имеют различные оптические применения $[2,3]$. В зависимости от физической природы внешнего воздействия на хромогенный материал, существует следующая классификация: материалы изменяющие свой цвет или светопропускание под действием света - фотохромные (PhC); электрического напряжения - электрохромные (ЕС); температуры - термохромные (ThC); газа - газохромные (GhC), а также жидкие кристаллы (нематики PDLC $\&$ LCD) при воздействии электрического напряжения [4]. Электрохромные пленки привлекают все больший интерес широкого круга исследователей по всему миру, в связи с возможностью создания на их основе целого ряда устройств для оптоэлектроники и фотоники: элементы отображения информации, «Smart Window», световые жалюзи, интеллектуальные зеркала и др. [5-7].

Электрохромное устройство (ECD) предполагает использование прозрачных проводящих покрытий или прозрачного электрода, более распространён ITO-электрод $\left(\left(\mathrm{In}_{2} \mathrm{O}_{3}\right)_{0,9}-\left(\mathrm{SnO}_{2}\right)_{0,1}\right)$, ме- нее распространенным является FТО-электрод $\left(\mathrm{SnO}_{2}: \mathrm{F}\right)$ необходимый для электрического управления устройством вывода информации (дисплей) или ИК-отражающего устройства для рассеивания тепловой энергии энергосберегающих окон «Smart Window» [8]. Основной проблемой использования ITO-покрытия для технологий-ЕС является ограниченность ресурсов для их производства, что в значительной степени удорожает технологию. По современным оценкам, запасы индия, который является основным элементом прозрачного электрода ITO будут исчерпаны в ближайшие 20 лет [9], что связано со значительным ростом использования ITO для смартфонов [10]. Начиная с 2009 года рынок «Smart-window» расширяется за счёт увеличения популярности и востребованности стекол с регулируемой прозрачностью [11].

Альтернативной заменой ITO и FTO являются полимеры и углеродные наноматериалы. Органические полимеры поли (3,4-этилендиокситиофен) или PEDOT имеет несколько преимуществ перед ITO, таких как гибкость, простота печати и не высокая стоимость. Тонкий слой углеродных нанотрубок (УНТ), также является перспективным вариантом из-за их высокой электропроводности. Электроды на основе графена [12] и его модификаций также имеют высокую степень электропровод- 
ности [13] и коэффициент светопропускания [14]. Углеродные наноматериалы находят широкое применение в ряде ЕС-устройств [15].

Электрохромные пленки $\mathrm{WO}_{3}$ могут быть получены разными методами в результате использования различных технологий, таких, как магнетронное напыление [16], золь-гель [17], химическое осаждение из паровой фазы [18], электрохимическое осаждение [19], спрей-пиролиз [20] и т.д. Перечисленные выше методы имеют как свои преимущества, так и недостатки. Электрохимическое осаждение привлекает особое внимание, так как не требует сложного дорогостоящего оборудования, а также в процессе осаждения допускает возможность контроля толщины пленки путем мониторинга расхода заряда во время осаждения [21-24] при этом автоматизация и контроль параметров пленки могут быть достигнуты без применения сложного аппаратного оформления. Следует, отметить возможность комбинированного электрохимического осаждения металлических компонентов из раствора электролита.

Поэтому целью данной работы являлось исследование оптических и электромагнитных свойств пленок $\mathrm{WO}_{3}$ модифицированных $\mathrm{GO}$, полученных методом электрохимического осаждения при разных режимах электроосаждения и составах электролита.

Для реализации поставленной цели, решались следующие задачи:

- получение пленок $\mathrm{WO}_{3}(\mathrm{GO})$ методом электрохимического осаждения при различных режимах;

- исследование спектральных свойств электрохромных пленок $\mathrm{WO}_{3}(\mathrm{GO})$ в диапазоне длин волн $250 . .1100$ нм;

- исследование электрохимического импеданса электрохромной пленки $\mathrm{WO}_{3}(\mathrm{GO})$;

- исследование электромагнитных свойств нанокомпозиционной пленки $\mathrm{WO}_{3}(\mathrm{GO})$ в диапазоне частот $2,65 \cdot 10^{10}-4,0 \cdot 10^{10} \Gamma ц$ (Ка - диапазон).

\section{Материалы \\ и методы исследования}

Получение раствора электролита на основе $\mathbf{W}_{2} \mathbf{O}_{11}{ }^{2-}$. Катодное гальваническое покрытие $\mathrm{WO}_{3}$ было получено в результате восстановления $\mathrm{O}_{2}$ или $\mathrm{H}_{2} \mathrm{O}$, что в свою очередь вызывает осаждение присутствующих ионов металла в растворе электролита в виде оксида или гидроксида металла основано на локальном увеличении $\mathrm{pH}$ вблизи поверхности электрода. Получение перокси-вольфрамовой кислоты $\mathrm{W}_{2} \mathrm{O}_{11}{ }^{2-}$ основывается на образовании перокситольфрамата промежуточное соединение из вольфрамовой соли (или из реакции металлического вольфрама с перекисью водорода), как описано в уравнениях 1 и 2 :

$$
\begin{aligned}
& 2 \mathrm{WO}_{4}{ }^{2-}+4 \mathrm{H}_{2} \mathrm{O}_{2}+2 \mathrm{H}^{+} \rightarrow \mathrm{W}_{2} \mathrm{O}_{11}{ }^{2-}+5 \mathrm{H}_{2} \mathrm{O} \\
& \mathrm{W}_{2} \mathrm{O}_{11}{ }^{2-}+2 \mathrm{H}^{+} \rightarrow 2 \mathrm{WO}_{3}+2 \mathrm{O}_{2}+\mathrm{H}_{2} \mathrm{O}
\end{aligned}
$$

Реакции (1) и (2) протекали экзотермически с интенсивным выделением $\mathrm{H}_{2}$ и образованием бесцветного раствора. Процесс окисления $\mathrm{W}$ контролировался температурой в пределах $40^{\circ} \mathrm{C}$, в конце активной фазы растворения $\mathrm{W}$, избыток $\mathrm{H}_{2} \mathrm{O}_{2}$ удаляли добавлением катализатора Pt-черной за счет разложения. В [25] отмечается, что концентрация $\mathrm{H}_{2} \mathrm{O}_{2}$ является важным параметром для электроосаждения. В полученный раствор электролита перокси-вольфрамовой кислоты $\mathrm{W}_{2} \mathrm{O}_{11}{ }^{2-}$ добавляли различную концентрацию GO (1 и 2 мл) и обрабатывали ультразвуком в течение 5 мин.

Метод электрохимического осаждения. На очищенную поверхность приготовленных ITOэлектродов осаждали пленки $\mathrm{WO}_{3}$ при переменном потенциале $(-0,5 \ldots-1,5$ В), при этом воздействие потенциала значение $-0,5$ В продолжалось в течение 15 с для осаждения $\mathrm{W}^{+}$, и $-1,5$ В в течение 0,5 с для осаждения $\mathrm{GO}^{-}$соответственно. Механизм электроосадения $\mathrm{W}_{2} \mathrm{O}_{3}$ может быть описан с помощью реакции (3):

$$
\begin{aligned}
& \mathrm{W}_{2} \mathrm{O}_{11}^{2-}+(2+3 x) \mathrm{H}^{+}+3 x e^{-} \rightarrow \\
& \rightarrow 2 \mathrm{H}_{x} \mathrm{WO}_{3}+(2+x) / 2 \mathrm{H}_{2} \mathrm{O}+(8-x) / 4 \mathrm{O}_{2}
\end{aligned}
$$

Для приготовления пленок $\mathrm{WO}_{3}$ (рис. 1) раствор электролита $\mathrm{W}_{2} \mathrm{O}_{11}{ }^{2-}$ подмешивали для равномерного распределения катионов $\mathrm{W}^{+}$и $\mathrm{GO}$

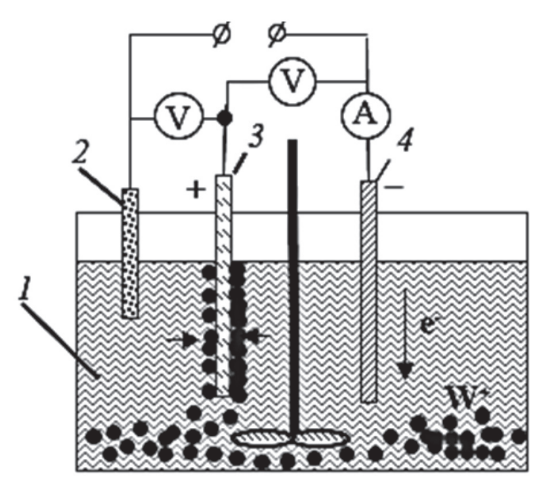

Рис. 1. Электрохимическая ячейка для получения электрохромных пленок $\mathrm{WO}_{3}(\mathrm{GO})$ 1 - электролит $\mathrm{W}_{2} \mathrm{O}_{11}{ }^{2-}(\mathrm{GO})$;

2 - электрод сравнения $\mathrm{Ag} / \mathrm{AgCl}(3 \mathrm{M} \mathrm{KCl})$; 3 - рабочий электрод IТО-стекло; 4 - противоэлектрод Pt-проволока 
на поверхности ITO-электрода в соответствии [26]. После завершения эксперимента полученные пленки обрабатывались деионизированной водой для снятия ионов из электролита $\mathrm{W}_{2} \mathrm{O}_{11}{ }^{2-}(\mathrm{GO})$.

\section{Методика исследования электромагнитных свойств $\mathrm{WO}_{3}(\mathrm{GO})$}

Исследование процессов взаимодействия электромагнитного излучения (ЭМИ) с образцами электрохромных пленок проводились в прямоугольном волноводном тракте, в диапазоне частот 26,5-40 ГГц (Ка-дипазон) на векторном анализаторе цепей N5290A Keysight Technologies (США). Размер образцов составлял 7,112×3,556×1 мм, который был связан с размерами используемого волновода, определяющего частотный диапазон. В качестве выходных характеристик выступали комплексные $\mathrm{S}$-параметры пропускания и отражения, представляющие собой отношение амплитуд прошедшего через образец сигнала к падающему на образец сигналу $\left(\mathrm{S}_{21}\right)$ и отраженного от образца сигнала к падающему на образец сигналу соответственно $\left(\mathrm{S}_{11}\right)$.

Расчет коэффициентов отражения и прохождения ЭМИ производился при помощи системы уравнений (3):

$$
\left\{\begin{array}{l}
K_{\text {Прох }}=\left(\mathrm{S}_{21}\right)^{2} \\
K_{\text {Omp }}=\left(\mathrm{S}_{11}\right)^{2} \\
K_{\text {Погл }}=1-\left(\mathrm{S}_{21}\right)^{2}-\left(\mathrm{S}_{11}\right)^{2}
\end{array}\right.
$$

\section{Метод спектрофотометрии}

Светопропускание образцов $\mathrm{WO}_{3}(\mathrm{GO})$ исследовали с помощью измерительной системы компании Avantes (Голландия), состоящей из источника света AvaLight-DHc и спектрометра Ava Spec-

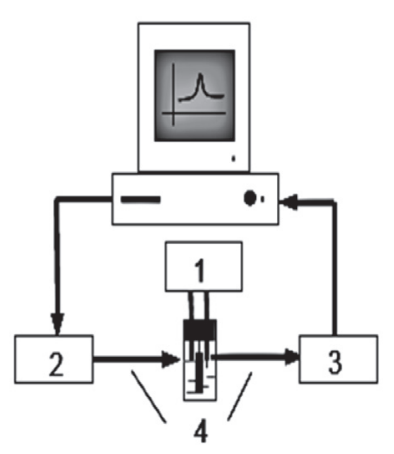

Рис. 2. Схема измерительной системы AvaLight-DHc/AvaSpec-ULS2048CL-EVO-RS

1 - потенцииостат, 2-источник света, 3 -спектрометр, 4-оптоволокно
ULS2048CL-EVO-RS (рис. 2). Управляющий электрический сигнал генерировался по заданной программе потенциостатом PalmSens 4 (Нидерланды). Измерения выполняли в закрытой оболочке, защищающей электрохромную ячейку от попадания солнечного света, в соответствии с методикой, описанной в [27].

\section{Метод электрохимического импеданса электрохромных пленок $\mathrm{WO}_{3}$ (GO)}

Электрохимический импеданс измеряли в диапазоне частот тока $(\omega) 20$ кГц $-0,05$ Гц с амплитудой переменного напряжения $10 \mathrm{MB}$ с использованием электрохимического измерительного комплекса PalmSens 4. Электродом сравнения служил $\mathrm{Ag} / \mathrm{AgCl}$ в 3M KCl. Образцы электрохромных пленок $\mathrm{WO}_{3}(\mathrm{GO})$ помещали в раствор электролита 0,01 $\mathrm{M} \mathrm{H}_{2} \mathrm{SO}_{4}$ Эквивалентная схема электрохромного процесса представлена на рис. 3 .

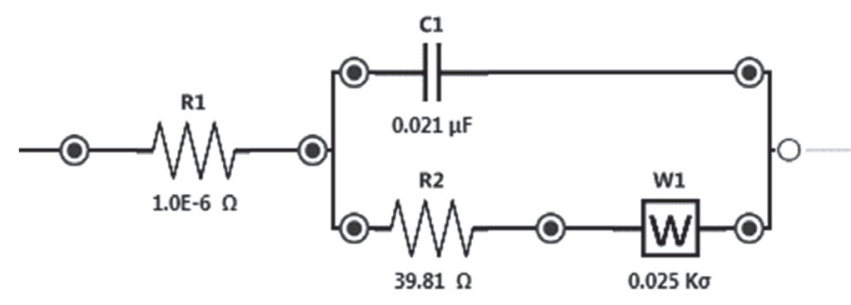

Рис. 3. Эквивалентная схема

R1, R2 - сопротивление, C1-емкость, W1-элемент Вабурга

Значения сопротивлений и емкости представленных на рис. 3 были выполнены с помощью программного комплекса PSTrace 5.7.

\section{Метод диагностирования структуры образцов электрохромных пленок $\mathrm{WO}_{3}$ (GO)}

Микроструктура полученных электрохромных пленок $\mathrm{WO}_{3}(\mathrm{GO})$ была исследована с помощью просвечивающего электронного микроскопа Hitachi H-800 с приставкой сканирующей электронной микроскопии Hitachi H-8010.

\section{ЭКСПЕРИМЕНТАЛЬНЫЕ РЕЗУЛЬТАТЫ И ОБСУЖДЕНИЕ}

В результате электрохимического осаждения были получены электрохромные пленки $\mathrm{WO}_{3}(\mathrm{GO})$ при различной концентрации GO (1 и 2 мл), в течение $15 . .120$ мин. Параметры образцов полученных 
Параметры электрохимического осаждения

\begin{tabular}{|c|c|c|c|}
\hline $\mathrm{WO}_{3}\left(\mathrm{GO}_{\mathrm{x}}\right)$ & $\begin{array}{c}\text { Время электрохимического } \\
\text { осаждения, мин }\end{array}$ & Напряжение, В & Плотность тока, мА/см${ }^{2}$ \\
\hline Образец № 1 & 15 & $-0,4$ & 6,25 \\
\hline Образец №2 & 30 & $-0,4$ & 6,25 \\
\hline Образец №3 & 60 & $-0,5$ & 6,25 \\
\hline Образец №4 & 120 & $-0,5$ & 6,25 \\
\hline
\end{tabular}
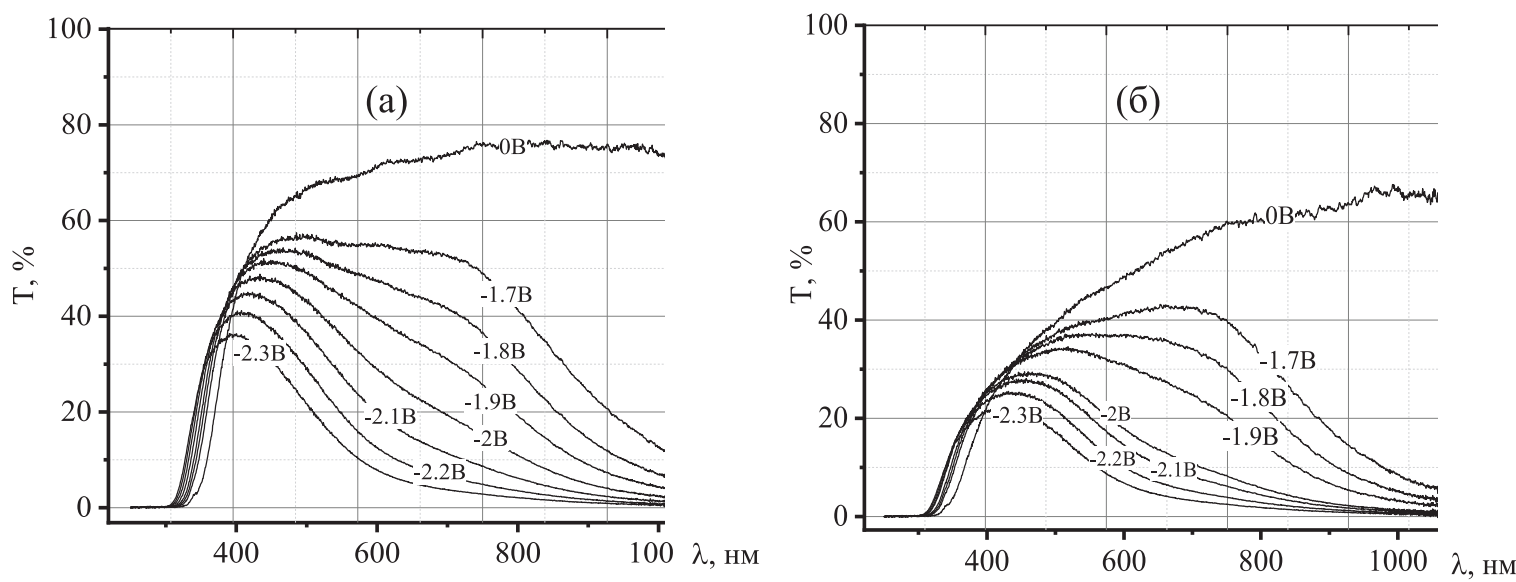

Рис. 4. Спектры оптического пропускания пленок WO хроноамперометрии, для окрашенного/ обесцвеченного состоянии

(a) $\mathrm{WO}_{3} 25$ тM ПВК-GO (10\%); (-0,5 - -1,5 B; 3000 ииклов);

(б) $\mathrm{WO}_{3} 25 \mathrm{mM} \Pi$ ПВK-GO (20\%); (-0,5 --1,5 В; 3000 ичиклов)

в процессе электрохимического осаждения представлены в табл. 1.

Спектральные зависимости (рис. 4) электрохромных пленок $\mathrm{WO}_{3}(\mathrm{GO})$ были исследованы с помощью метода спектрофотометрии. На рис. 4а представлены образцы электрохромных пленок, модифицированных 1 мл GO и 2 мл GO (рис. 4б). Из рис. $4 б$ видно, что при увеличении концентрации GO, возрастает коэффициент светопоглощения относительно рис. 4а. Для образца в исходном состоянии рис. 4 а коэффициент светопропускания имеет значение около $80 \%$, а на рис. 46 около $70 \%$, что говорит о влиянии внесенной добавки GO. При этом диапазон рабочего напряжения для исследуемых образцов составлял [0...-2,3 B], в процессе активации электрохромные пленки $\mathrm{WO}_{3}(\mathrm{GO})$ обратимо окрашивались от светло-голубого до темносинего. Механизм электрохромной реакции представлен в (4):

$$
\underbrace{\mathrm{WO}_{3}(\mathrm{GO})+x \mathrm{H}^{+}+x e^{-}}_{\text {обесцвеченньй }} \leftrightarrow \underbrace{\mathrm{H}_{x} \mathrm{WO}_{3}(\mathrm{GO})}_{\text {синий или черньй }}
$$

Для напряжения минус 3В, пленки окрашивались в черный цвет, при таком уровне напряжения

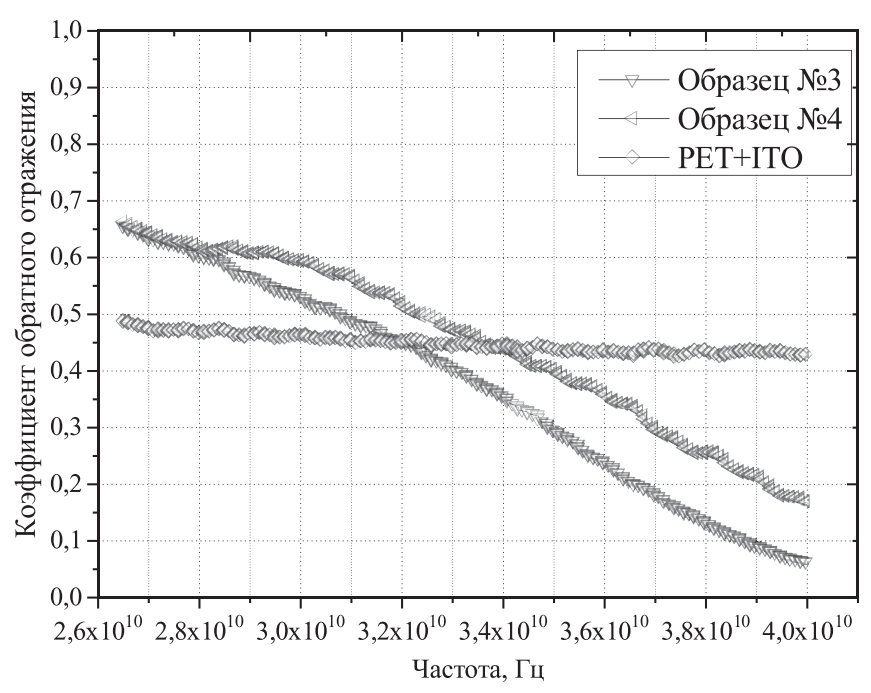

Рис. 5. Графическое представление коэффициента обратимого отражения ЭМИ через электрохромные образцы $\mathrm{WO}_{3} / \mathrm{GO}$

время модуляции электрохромного слоя значительно увеличивалось от нескольких секунд до нескольких минут, а количество рабочих циклов уменьшалось до несколько десятков. 
Исследование процессов взаимодействия ЭМИ с образцами электрохромных пленок $\mathrm{WO}_{3}(\mathrm{GO})$ производилось в диапазоне частот 26,5-40 ГГц (Кадипазон). Для изучения влияния комбинированного слоя $\mathrm{WO}_{3} / \mathrm{GO}$ на общие магнитные свойства, был отдельно измерен и проанализирован магнитный коэффициент обратимого отражения для ITOэлектрода на РЕТ подложки (рис. 5.).

Пилообразный характер кривой PET/ITO, представленной на рис. 5, обусловлен интерференцией, происходящей на границах перехода между воздухом и тонким проводящим слоем ITO, а также РЕТ-подложкой. За счет высокой проводимости ITО-слоя, близкого к металлической, наблюдается высокое значение отражения на границе: $\mathrm{WO}_{3}(\mathrm{GO})$ - ITO-слой. Учитывая то, что слой тонкий, излучение отражается не полностью, а проходит дальше, где на границе «ITO-слой - стекло» также происходит отражение, смещенное по фазе относительно первого, с увеличением времени электрохимического осаждения и концентрации GO в составе электрохромной пленки $\mathrm{WO}_{3}$ повышается магнитный коэффициент обратимого отражения. Предположительно, что в первом случае представленный эффект возможен благодаря решетчатой структуре, а во втором дополнительному электропроводящему слою. Данные результаты сопоставимы с электрохромными пленками $\mathrm{WO}_{3}(\mathrm{GO})$ полученных в работе [27].

Изображения микроструктуры исследуемых образцов представлены на рис. 6. Образец № 1 представлен на рис. $6 \mathrm{a}$, исходя из СЭМ-снимка можно оценить равномерность распределение кристаллических частиц $\mathrm{WO}_{3}$ на поверхности ITO-электрода, которая представлена четко выраженным массивом. Затемнённая область вокруг кристаллических частиц $\mathrm{WO}_{3}$ является осажденным $\mathrm{GO}$, которая занимает большую часть изображения. Образец №2 показан на рис. 6б, видно более плотную конфигурацию активных частиц $\mathrm{W}_{2} \mathrm{O}_{3}$, результаты сопоставимы с полученными в [28]. На рис. 6в показан образец № 3 с максимальным распределением частиц $\mathrm{WO}_{3}$, имеющий наибольшее количество частиц $\mathrm{WO}_{3}$ на поверхности IТО-электрода. Образец № 4 (рис. 6г) из-за длительного времени осаждения имеет разбитую поверхность в виде
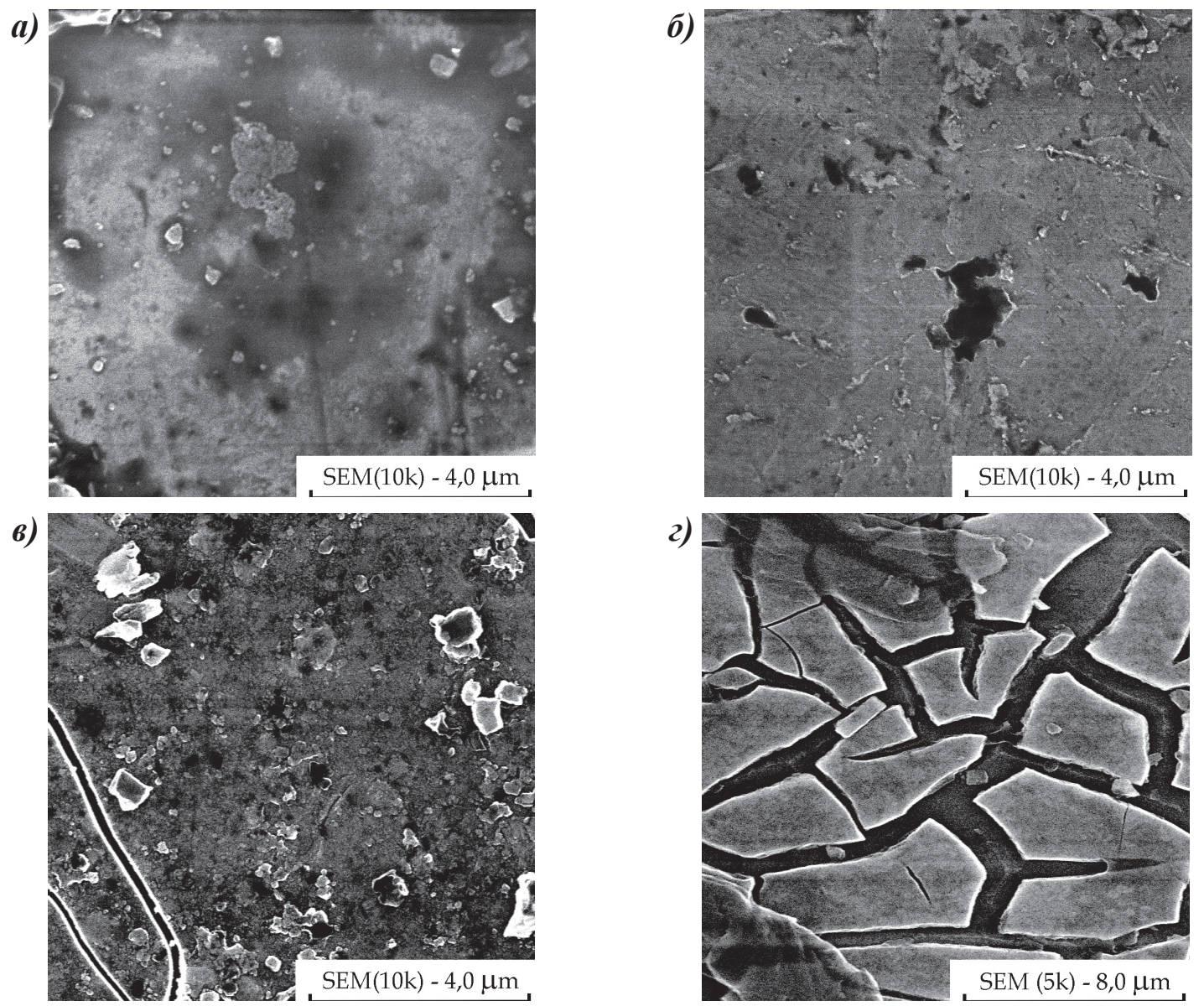

Рис. 6. Изображения СЭМ микроструктуры электрохромных пленок $\mathrm{WO}_{3}(\mathrm{GO})$ a) образеи №1: $\mathrm{WO}_{3}\left(G O_{2 m}\right)(-0,4 \ldots-1,5 \mathrm{~B}, 15 \mathrm{мuн})$; б) образеи №2: $\mathrm{WO}_{3}\left(G O_{I m l}\right)(-0,4 \ldots-1,5 \mathrm{~B}, 30$ мин $)$; в) образеи №3: $\mathrm{WO}_{3}\left(G O_{2 m}\right)\left(-0,5 \ldots-1,5 \mathrm{~B}, 60\right.$ мин); г) образеи №1: $\mathrm{WO}_{3}\left(G O_{1 m}\right)(-0,5 \ldots-1,5 \mathrm{~B}, 120$ мин $)$ 

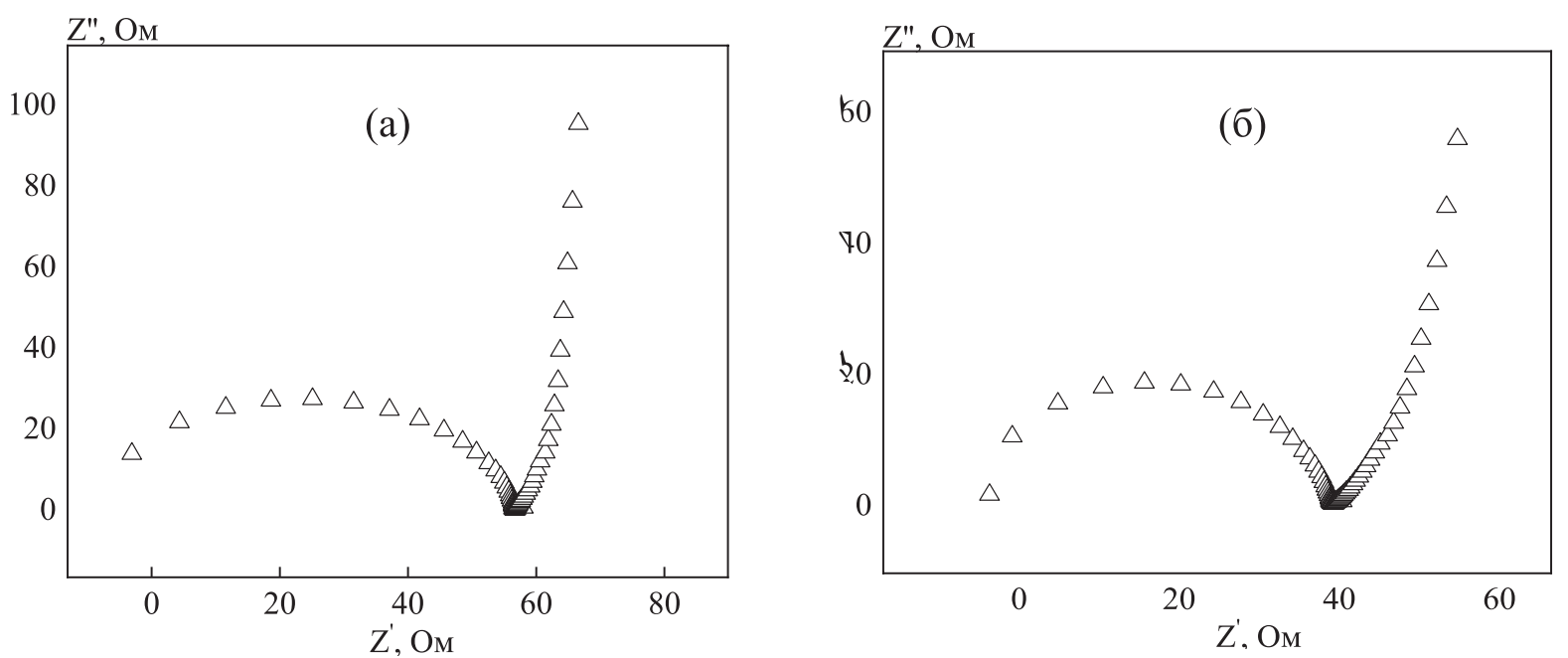

Рис. 7. Годографы электрохромных пленок $\mathrm{WO}_{3}(\mathrm{GO})$ полученных электрохимическим осаждением

(a) $\mathrm{WO}_{3} 25 \mathrm{mM} \mathrm{\Pi ВK-GO}(10 \%)(-0,5--1,5 \mathrm{~B} ; 3000$ ичиклов);

(б) $\mathrm{WO}_{3} 25 \mathrm{mM} \mathrm{ПВK-GO} \mathrm{(20 \% )} \mathrm{(-0,5--1,5} \mathrm{В;} 3000$ цчиклов)

мозаики, с четко регистрируемыми отдельными частями пленки.

Для того, чтобы оценить влияние концентрации GO и вклада зернистой структуры (рис. 6) на общую проводимость, было проведено сравнение двух образцов электрохромных пленок $\mathrm{WO}_{3}(\mathrm{GO})$. На рисунках 7а и $7 б$ показан различный характер изменения электрохромного импеданса пленок $\mathrm{WO}_{3}$. Измерения производились по эквивалентной схеме замещения представленной на рис. 3.

Различие кривых показанных на рис. 7а и $7 б$ вызвано изменением электропроводимости, что можно объяснить уменьшением поверхностного сопротивления пленок $\mathrm{WO}_{3}$, связанным с лучшим транспортом ионов в образовавшейся пористой структуре GO. Следует также отметить, что этот эффект связан с образованием более плотной поверхностной упаковки атомов $\mathrm{W}^{+}$на подложке ITO и, как следствие, лучшим переносом носителей заряда. На основании чего можно предположить, что формирование упорядоченной структуры улучшает ионный транспорт на поверхности пленки и, следовательно, скорость электрохимической реакции увеличивается.

\section{Заключение}

Разработана методика электрохимического осаждения частиц $\mathrm{WO}_{3}$ из наномодифицированного электролита $\mathrm{W}_{2} \mathrm{O}_{11}{ }^{2-}(\mathrm{GO})$, были получены нанокомпозиционные электрохромные пленки $\mathrm{WO}_{3}(\mathrm{GO})$ на прозрачном электроде-ITO при 1 и 2 мл GO и времени осаждения $15 . .120$ мин . В ре- зультате внесенной добавки GO в раствор электролита $\mathrm{W}_{2} \mathrm{O}_{11}{ }^{2-}$ были получены следующие положительные эффекты:

- Увеличение концентрации GO способствовала повышению светопоглощательной способности в диапазоне длин волн 250-1100 нм при напряжении $-1.7 \ldots-2.2$ В происходило снижение прозрачности в ИК-области в сочетании с ростом прозрачности в коротковолновой УФ и видимой области спектра.

- Установлено, что при увеличении концентрации GO уменьшается коэффициент электромагнитного пропускания.

- Выявлено влияние структуры и содержания GO на электропроводящие свойства. Образцы электрохромных пленок $\mathrm{WO}_{3}(\mathrm{GO})$ с бо́льшим содержанием GO, меньшей зернистостью и более плотной упаковки атомов W, обладают лучшей электропроводностью. Структура поверхности электрохромных пленок $\mathrm{WO}_{3}(\mathrm{GO})$ зависит от потенциала электрохимического осаждения, а также от времени нанесения.

Оптические и электромагнитные свойства, также зависят от времени получения, электрического потенциала электроосаждения, т.е. при увеличении времени осаждения, уменьшается коэффициент электромагнитного пропускания. Интенсивность светопоглощательной способности пленок $\mathrm{WO}_{3}(\mathrm{GO})$ - повышалась за счёт увеличения потенциала электроосаждения. Предположительно, что в первом случае данный эффект возможен благодаря образованию дополнительного электропроводящего слоя $\mathrm{GO}$, а во втором - решетчатой структуре и увеличенной толщине активного слоя. 
Электрохромные нанокомпозиционные пленки $\mathrm{WO}_{3}(\mathrm{GO})$ полученные методом электрохимического осаждения, могут эффективно модулировать отражения в области оптического излучения - обеспечивая эффект светофильтра и экранировать ЭМИ. Установлено, что оптимальным режимом электрохимического осаждения является: $-0,4$ В с выдержкой 30 мин.

Исследование выполнено при финансовой поддержке РФФИ в рамках научного проекта № 18 53-00032 Бела.

\section{Лumepamypa}

1. Bamfield P. Chromic Phenomena the Technological Applications of Colour Chemistry, Royal society of Chemistry (RSC). 2001. p. 374.

2. Addington D.M., Schodek D.L. Smart Materials and New Technologies for the architecture and design professions, Elsevier Science. Oxford. 2005. P. 241.

3. Zhao Y., Ikeda T. Smart Light-responsive materials. Azobenze-Containing Polymers and Liquid Crystals, A John Wiley \& Sons, Inc. 2009. P. 514.

4. Granqvist C.G., Green S., Niklasson G.A., Mlyuka N.R., Kraemer S., Georen P. Thin Solid Films. 2010. V. 518. P. 3046-3053. DOI: 10.1016/j.tsf.2009.08.058.

5. Pettersson H., Gruszecki T., Johanson L.-H., Edwards M.O.M., Hagteldt A., Matuszczyk T. Displays. 2004. V. 25. P. 223-230.

6. Somani P.R., Radhakrishman S. Materials Chemistry and Physics. 2002. V. 77. P. 117-133. DOI: 10.1016/ S0254-0584(01)00575-2.

7. Lampert C.M. Solar Energy Materials \& Solar Cells. 2003. V. 76. P. 489-499. DOI: 10.1016/S09270248(02)00259-3.

8. Granqvist C.G. Solar Energy Materials and Solar Cells. 2007. V. 91. P. 1529-1598. DOI: 10.1016/j.solmat.2007.04.031.

9. Интернет ресурс: http://mineralpro.ru/minerals/ indium/.

10. Indium Tin Oxide and Alternative Transparent Conductor Markets, NanoMarkets study (2009) http://www. criticalrawmaterials.eu/indium-tin-oxide-and-alternative-transparent-conductor-markets/.

11. Донизова А.Е., Калинина А.B. Alfabuild. 2018. V. 4(6). P. 73-82.

12. Novoselov K.S. Nobel Lecture: Graphene: Materials in the Flatland, Reviews of modern physics. 2011. V. 83 P. 837-849. DOI:10.1103/RevModPhys.83.837.

13. Wassei J.K., Kaner R.B. Materials Today. 2010. V. 13. Is. 3. P. 52-59. DOI: 10.1016/S1369-7021(10)70034-1.

14. Avouris P. NanoLetters. 2010. V. 10. P. 4285-4294. DOI: $10.1021 / \mathrm{nl} 102824 \mathrm{~h}$.

15. Moser L.M., Li G., Chen M., Bekyarova E., Mikhail E.I., Haddon R.C. NanoLetters. 2016. V. 16. Is. 9. P. 53865393. DOI: 10.1021/acs.nanolett.6b01564.

16. Hodes G., Cahen D., Manassen J. Nature. 1976. V. 260. P. 312-313.

17. Zhang G., Lu K., Zhang X., Yuan W., Shi M., Ning H., Tao R., Liu X., Yao R., Peng J. Micromachines. 2018. V. 9. N. 8. P. 377-386.

18. Granqvist C.G. Handbook of Inorganic Electrochromic Materials. Amsterdam, Elsevier Science. 1995. 633 p.

19. Zhenrui Y., Xiaodong J., Jinhui D., Jiayou Z. Solar Energy Materials \& Solar Cells. 2000. V. 64. P. 55-63.

20. Kumar A., Prajapati C.S., Sahay P.P. Journal of Sol-Gel Science and Technology. 2019. V. 90. N. 2. P. 281-295.

21. Pauporte T.A. Journal of The Electrochemical Socity. 2002. V. 149. N. 11. P. 539-545.

22. Shiyanovskaya I., Hepel M., Tewksburry E. Journal of New Materials for Electrochemical Systems. 2000. V. 3. P. 241-247.

23. Santos L., Neto J.P., Crespo A., Baiao P., Barquinha P., Pereira L., Martins R., Fortunato E. Electroplating of Nanostructures. 2015. P. 27-47.

24. Poongodi S., Kumar P.S., Mangalaraj D., Ponpandian N., Meena P., Masuda Y., Lee C. Journal of Alloys and Compounds. 2017. V. 719. P. 71-81.

25. Meulenkamp E.A. Journal of The Electrochemical Society. 1997. V. 144. N. 5. P. 1664-1671.

26. Щегольков А.В., Щегольков А.В. Перспективные материалы. 2020. № 1. С. 54-63.

27. Щегольков А.В., Парфимович И.Д., Комаров Ф.Ф., Щегольков А.В., Туголуков Е.Н. Вопросы материаловедения. 2020. № 1. С. 85-96.

28. Kwong W.L., Qiu H., Nakaruk A., Koshy P. Sorrell C.C. Energy Procedia. 2013. V. 34. P. 617-626. 